\title{
Miribel - Tramoyes - Beynost - La Boisse
}

Autoroute A 432 section La Boisse- Les Echets

\section{Franck Gabayet}

\section{(2) OpenEdition}

\section{Journals}

Édition électronique

URL : http://journals.openedition.org/adlfi/3409

ISSN : 2114-0502

Éditeur

Ministère de la culture

Référence électronique

Franck Gabayet, " Miribel - Tramoyes - Beynost - La Boisse », ADLFI. Archéologie de la France-

Informations [En ligne], Rhône-Alpes, mis en ligne le 01 mars 2009, consulté le 19 avril 2019. URL

http://journals.openedition.org/adlfi/3409

Ce document a été généré automatiquement le 19 avril 2019

(C) Ministère de la Culture et de la Communication, CNRS 


\title{
Miribel - Tramoyes - Beynost - La Boisse
}

\author{
Autoroute A 432 section La Boisse- Les Echets
}

Franck Gabayet

\section{Identifiant de l'opération archéologique : 9966}

Date de l'opération : 2009 (EX)

Le projet de construction de l'ultime section de l'autoroute A 432, entre les communes de La Boisse (Ain) et celle de Cailloux-sur-Fontaine (Rhône), soit une dizaine de kilomètres environ pour une emprise de l'ordre de 80 ha, est à l'origine d'une prescription de diagnostic archéologique engagée par le Service régional de l'archéologie (SRA) RhôneAlpes. L'intervention archéologique concerne quatre communes : respectivement d'ouest en est, Miribel, Tramoyes, Beynost et La Boisse.

2 L'emprise archéologique définie par le SRA se limite à environ 70 ha desquels doivent être retranchés près de 18 ha non accessibles au moment de l'opération.

Ce sont ainsi 746 tranchées disposées en quinconce d'une surface d'environ $30 \mathrm{~m}^{2}$ et d'une largeur de $2 \mathrm{~m}$ qui ont pu être réalisées. La présence d'anomalies a pu entraîner ponctuellement une densification des sondages et un élargissement des tranchées initiales. Dans les cas de présence avérée de vestiges archéologiques, des fenêtres ont été ouvertes pour préciser la nature et la puissance du gisement en termes d'épaisseur, voire l'orientation de structures linéaires.

4 A proximité du sillon rhodanien, qui constitue à toutes les époques un axe de circulation majeur, le tracé autoroutier traverse la frange méridionale du plateau de la Dombes, en bordure de l'ancien marais des Echets. Cette situation explique, au moins pour partie, une fréquentation, dès la Préhistoire, par des groupes humains venus de l'Europe continentale, nordique ou méditerranéenne (Motte et al., 1999). Localement, le milieu naturel, et en particulier le Marais constitue un réel pôle d'attraction quelle que soit l'époque. 
5 Les sondages ont livré environ 160 structures, le plus souvent en creux, réparties de manière inégale sur l'ensemble du tracé. Toutes les grandes périodes chronologiques sont représentées, la Préhistoire livrant quelques pièces lithiques attribuées à l'Épipaléolithique et au Néolithique final, mais aussi un mobilier céramique du Néolithique final II qui peut-être associé à un réseau fossoyé (lieu-dit Les Abéroux).

6 La Protohistoire compte de nombreuses fosses de toutes dimensions, avec notamment une fosse à pierres chauffées (Le bois de Côte-Michon), mais également un secteur funéraire comportant au moins trois tombes à crémations (Les Abéroux). Les périodes les plus anciennes de l'âge du Bronze ne sont guère présentes des tessons épars et c'est surtout la période du Bronze final qui prédomine très largement. L'âge du Fer est représenté par quelques éléments attribués au Hallstatt $C$, mais aussi à la fin de La Tène (le Grand-Charmillieu, le bois de Côte-Michon).

7 Pour la période antique, c'est essentiellement le Bas-Empire qui apparaît, sous la forme de plusieurs petits établissements caractérisés par la présence de fosses dépotoirs, de silos, voire de petites unités d'habitation construites sur poteaux. Le même type d'occupation est identifié pour la période du haut Moyen Age. Les découvertes les plus importantes sont localisées aux lieux-dits Creux-Marceaux et Grandes-Croix (commune de Beynost) dont les principales occupations, sans doute agricoles, sont datées entre les $\mathrm{Ill}^{\mathrm{e}}$ s.et VIle ${ }^{\mathrm{e}}$.

Les données archéologiques issues du diagnostic sont bien évidemment trop partielles, pour espérer retracer l'histoire de l'occupation de cette partie du plateau dombiste du Néolithique, voire l'Épipaléolithique, jusqu'au Moyen Age, en passant par les âges du Bronze, du Fer et l'Antiquité. Comme on pouvait s'y attendre, les secteurs occupés sont les parties hautes du plateau, les flancs de coteaux etc. tandis que les parties basses, où l'eau est présente en permanence, n'ont pas suscité d'intérêt pour implanter des habitats, sans être toutefois entièrement délaissées puisqu'elles sont systématiquement drainées par des fossés, parfois en nombre important. Quelle que soit la période, l'occupation des différents sites laisse entrevoir des installations de courte durée parfois évoquées sous l'appellation de "clairière culturale »: un territoire occupé de façon intermittente de la Préhistoire jusqu'au Moyen Âge, sans que l'habitat se fixe de manière pérenne.

\section{INDEX}

operation Expertise (EX)

Index chronologique : âge du Bronze, âge du Fer, Antiquité, Bas-Empire, Épipaléolithique, haut Moyen Âge, IIIe siècle apr. J.-C., IVe siècle apr. J.-C., Néolithique final, Ve siècle apr. J.-C., VIe siècle apr. J.-C., VIIe siècle apr. J.-C.

Index géographique : Rhône-Alpes, Ain (01), Boisse

Thèmes : bâtiment agricole, céramique, fossé, fosse-dépotoir, galet aménagé, habitat rural, incinération, silo, trou de poteau 
AUTEUR

FRANCK GABAYET

INRAP 